\title{
Anomalous Loss Hysteresis Loop
}

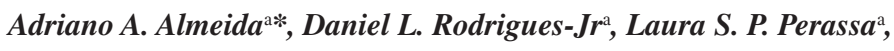 \\ Jeanete Leicht ${ }^{\mathrm{b}}$, Fernando J. G. Landgraf ${ }^{\mathrm{a}}$
}

\author{
${ }^{a}$ Escola Politécnica de Engenharia Metalúrgica e de Materiais, Universidade de São Paulo - USP, \\ CEP 05508-030, São Paulo, SP, Brasil \\ ${ }^{\mathrm{b}}$ University of Wales (Cardiff), United Kingdom
}

Received: July 1, 2013; Revised: January 16, 2014

\begin{abstract}
This paper discusses the anomalous loss behavior in two electrical steels types. Starting from a non oriented electrical steel coil, three groups of samples with different grain sizes were produced. Grain oriented steel samples were produced from a commercially available material. The experimental procedure was performed by means of magnetic properties measurements using an Epstein frame. A procedure to draw the hysteresis curve of the anomalous loss is proposed. The results reported that anomalous loss has a different behavior when the two electrical steel types are compared. In non oriented steels anomalous loss is concentrated at the low induction region. In grain oriented steels, a remarkable participation of high induction region is observed.
\end{abstract}

Keywords: anomalous loss, hysteresis curve, non oriented steel, grain oriented steel

\section{Introduction}

One of the most important parameters for electrical steel selection is magnetic loss. This feature refers to the energy dissipated when the material is cyclically magnetized and demagnetized. Magnetic loss, or iron loss, is commonly divided in three parcels: hysteretic (or quasi static), classical eddy current (or parasitic) and anomalous loss (the term excess loss is often used too). This analysis method has been applied by the industry for decades ${ }^{1}$.

Microestructural characteristics affect the three parcels behavior. Other publications ${ }^{2-5}$ reported that features like grain size and texture have influence over the hysteretic and anomalous loss.

While hysteresis loss is calculated as the area of a experimentally measured hysteresis loop, allowing the discussion of energy dissipation mechanisms ${ }^{6-8}$ in different areas of the curve, anomalous loss is obtained as the rest of a sum, giving no chance to such discussion. The present work proposes a procedure to draw the hysteresis of eddy current loss and, by geometrical differences, calculate and draw the hysteresis curve of anomalous loss. Applying these procedures to non oriented and grain oriented samples, energy dissipation mechanisms ${ }^{6-8}$ in anomalous loss are discussed.

\section{Experimental Procedure}

In this paper two kinds of electrical steels were analyzed: grain oriented steel (GO) and non oriented steel (NO). The GO steel was produced by Aperam with thickness $0.27 \mathrm{~mm}$, resistivity $49 \mu \Omega . \mathrm{cm}$, density $7650 \mathrm{Kg} / \mathrm{m}^{3}$, grain size $3 \mathrm{~mm}$ and chemical composition as described in Table 1. It was

*e-mail: adriano.aalex@usp.br made available in flat strips shape with dimensions $30 \times 3 \mathrm{~cm}$ and the rolling direction parallel to the length.

Non oriented electrical steel samples were extracted from a single coil, in annealed state, whose chemical composition is described in the Table 2. The initial thickness was $0.54 \mathrm{~mm}$, density $7780 \mathrm{~kg} / \mathrm{m}^{3}$, resistivity $25.67 \mu \Omega . \mathrm{cm}$ and grain size $11 \mu \mathrm{m}$.

This material was cut, giving rise to strips for magnetic characterization with size $30 \times 3 \mathrm{~cm}$ and length parallel to rolling direction. In order to produce sets of samples with different grain size a heat treatment was performed to provide grain size increasing by grain growth. The annealing parameters are described in Table 3.

The microstructural characterization was performed by means of micrographs extracted from a surface at mid thickness of the sample after metallographic preparation and chemical etching using Nital $3 \%$. The grain size measurement was performed using the intercept method in accord to ASTM standard9.

The analysis of the magnetic properties was made through a loss separation procedure, performed graphically. Therefore, hysteresis curves were produced corresponding to each of the portions that compose the total loss. Hysteresis loops related to total and hysteretic losses were directly obtained using an Epstein frame. In this equipment the primary current was supplied by a power amplifier KEPCO BOP50-80 with a waveform generator HP33120A/ dc-15 MHz. Sinusoidal induction with maximum value 1.5 T was used.

Total loss determination was measured by a wattmeter at frequency of $60 \mathrm{~Hz}$ for $\mathrm{NO}$ steel strips. For the GO steel samples tests at frequencies of 60 and $100 \mathrm{~Hz}$ were carried out. Hysteretic loss determination was made using 
Table 1. Chemical composition of the grain oriented electrical steel.

\begin{tabular}{ccccccccc}
\hline $\mathbf{S i}$ & $\mathbf{A l}$ & $\mathbf{S}$ & $\mathbf{C}$ & $\mathbf{N b}$ & $\mathbf{M n}$ & $\mathbf{C r}$ & $\mathbf{T i}$ \\
\hline 3.22 & 0.0014 & 0.0297 & 0.0369 & 0.0022 & 0.0563 & 0.0138 & 0.001 \\
\hline
\end{tabular}

Table 2. Chemical composition of the non oriented steel.

\begin{tabular}{cccccccccc}
\hline $\mathbf{C}$ & $\mathbf{M n}$ & $\mathbf{P}$ & $\mathbf{S}$ & $\mathbf{S i}$ & $\mathbf{C u}$ & $\mathbf{A l}$ & $\mathbf{N i}$ & $\mathbf{C r}$ & $\mathbf{T i}$ \\
\hline $24 \mathrm{ppm}$ & 0.5 & 0.016 & 0.0086 & 0.69 & 0.066 & 0.312 & 0.0108 & 0.025 & 0.001 \\
\hline
\end{tabular}

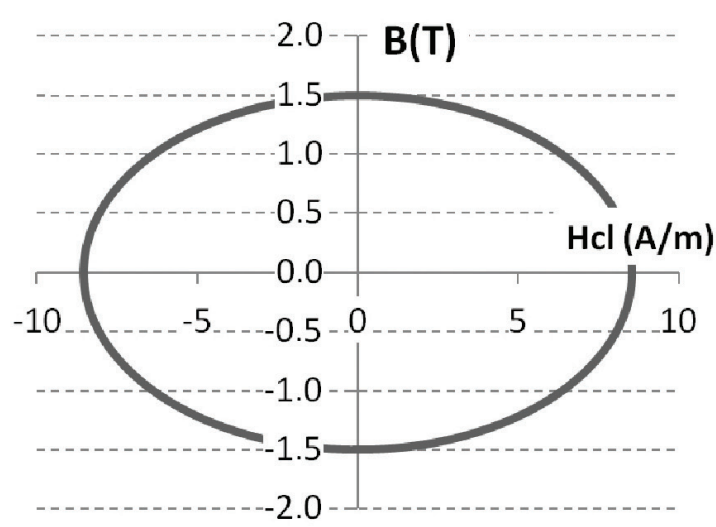

(a)

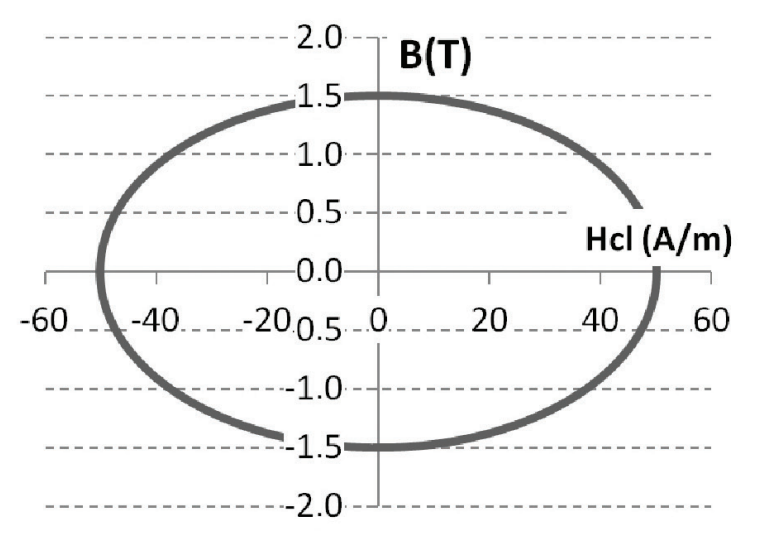

(b)

Figure 1. $\mathrm{B} \mathrm{x} \mathrm{H}_{\mathrm{cl}}$ loops for $\mathrm{GO}(\mathrm{A})$ and $\mathrm{NO}$ (B) samples for a magnetization cycle with maximum induction $1.5 \mathrm{~T}$ and frequency $60 \mathrm{~Hz}$.

a fluxmeter Walker MF-3D connected to the Epstein frame secondary coil and a shunt resistor connected to a multimeter HP 34401A, at $0.005 \mathrm{~Hz}$.

The eddy current loss calculation was carried out from the equation proposed by Bertotti ${ }^{10}$. The author describes a classical field, $\mathrm{H}_{\mathrm{cl}}$, whose origin is due to induced parasitic currents. The classical field, $\mathrm{H}_{\mathrm{cl}}$, is determined using Equation 1.

$H_{c l}(t)=\frac{\sigma \times t_{h}^{2}}{12} \times \frac{d B}{d t}$

where $\sigma$ is conductivity, $\mathrm{t}_{\mathrm{h}}$ is thickness and $d B / d t$ is the variation rate of induction, $\mathrm{B}$, as function of the time, $t$. Magnetic induction varies as a sinusoidal function of the time as reported by Equation 2 with $B_{m}$ meaning maximum induction.

$B(t)=B_{m} \times \cos (2 \pi f \times t)$

Thus, $\mathrm{dB} / \mathrm{dt}$ can be derived from Equation 2 as described in Equation 3

$\frac{\mathrm{dB}}{\mathrm{dt}}=-\mathrm{B}_{\mathrm{m}} 2 \pi \mathrm{f} \operatorname{sen}(2 \pi \mathrm{ft})$

where $f$ is the frequency.

Anomalous loss is treated here as a consequence of an anomalous field. Thus, it can be calculated in an analogue way to the traditional method for anomalous loss determination ${ }^{11}$, in other words, by subtraction of magnetic field values, at each induction level, as described by Equation 4.
Table 3. Annealing parameters and final grain size of the non oriented electrical steel samples.

\begin{tabular}{lccc}
\hline & A & B & C \\
\hline Temperature $\left({ }^{\circ} \mathrm{C}\right)$ & 600 & 850 & 850 \\
Time (hours) & 2 & 4 & 8 \\
Grain size after annealing $(\mu \mathrm{m})$ & 11 & 58 & 62 \\
\hline
\end{tabular}

Table 4. Comparison between the internal area of the $\mathrm{B} \times \mathrm{H}_{\mathrm{cl}}$ loops described in Figure 1 and classical eddy current loss estimated from Equation 5.

\begin{tabular}{llll}
\hline & \multicolumn{2}{c}{$\mathbf{P}_{\mathrm{cl}}\left(\mathbf{J} / \mathbf{m}^{3}\right)$} \\
\cline { 2 - 3 } & \multicolumn{2}{c}{ GNO } & \multicolumn{2}{c}{ GO } \\
\hline Thomson - Equation 6 & 231.26 & 33.28 \\
Área B x H & 230.9 & 33.61 \\
\hline
\end{tabular}

$H_{\text {anomalous }}^{B i}=H_{\text {total }}^{B i}-\left(H_{\text {classical }}^{B i}-H_{\text {histeretic }}^{B i}\right)$

\section{Results and Discussion}

\subsection{Eddy current loss}

Applying the equations previously presented in this paper one can note that the magnetic induction varies with classic field describing a closed ellipse as illustrated in Figure 1.

Table 4 shows a comparison between the internal area of the $\mathrm{B} \mathrm{x} \mathrm{H}_{\mathrm{cl}}$ loops described in Figure 1 and classical 


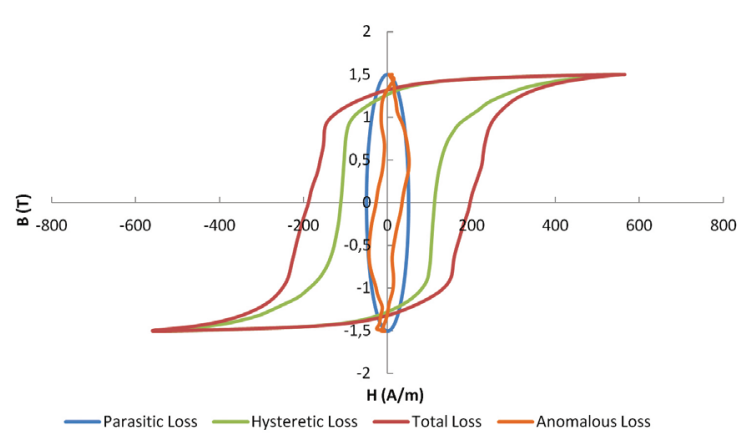

Figure 2. Loss separation for NO samples annealed for 2 hours at $600{ }^{\circ} \mathrm{C}$ with final grain size $11 \mu \mathrm{m}$ using peak induction $1.5 \mathrm{~T}$ and frequency $60 \mathrm{~Hz}$.

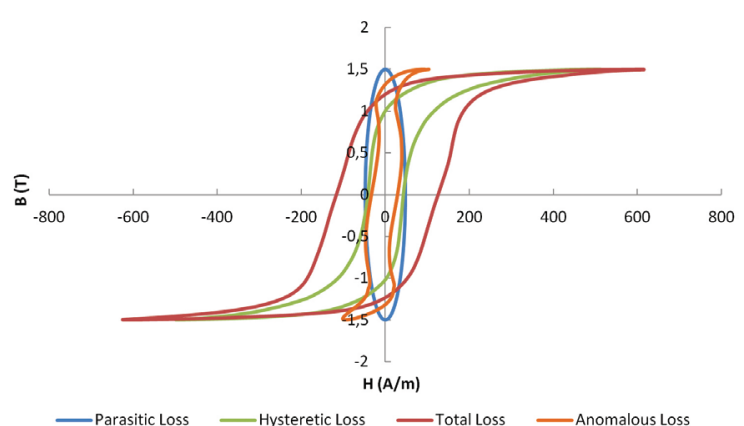

Figure 3. Loss separation for NO samples annealed for 4 hours at $850{ }^{\circ} \mathrm{C}$ with final grain size $58 \mu \mathrm{m}$ using peak induction $1.5 \mathrm{~T}$ and frequency $60 \mathrm{~Hz}$.

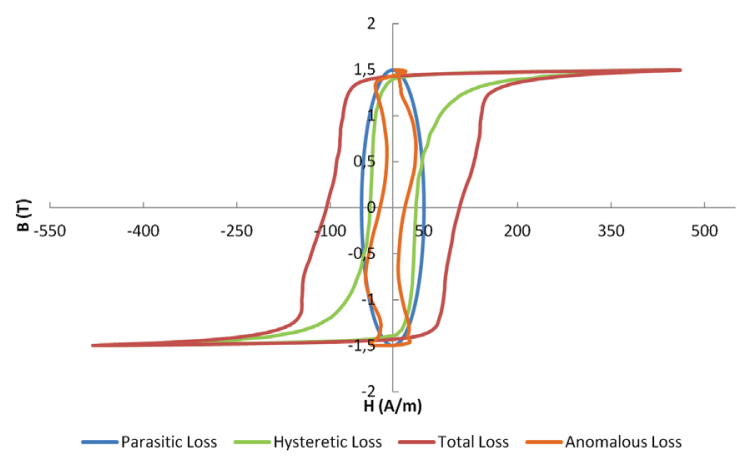

Figure 4. Loss separation for NO samples annealed for 8 hours at $850{ }^{\circ} \mathrm{C}$ with final grain size $62 \mu \mathrm{m}$ using peak induction $1.5 \mathrm{~T}$ and frequency $60 \mathrm{~Hz}$.

eddy current loss estimated from Equation 5, proposed by Thomson ${ }^{12}$, where $B_{m}$ is maximum induction, $\rho$ is resistivity and $\mathrm{d}$ is density. These results indicate that both methods are equivalent for parasitic loss calculation.

$P_{C l}=\frac{f\left(\pi B_{m} e\right)^{2}}{6 \rho}$

\subsection{Anomalous loss}

Hysteresis loops for total loss and its parcels are illustrated in Figures 2, 3 and 4 for non oriented steels with grain size 11,58 and $62 \mu \mathrm{m}$, respectively, and maximum induction $1.5 \mathrm{~T}$.

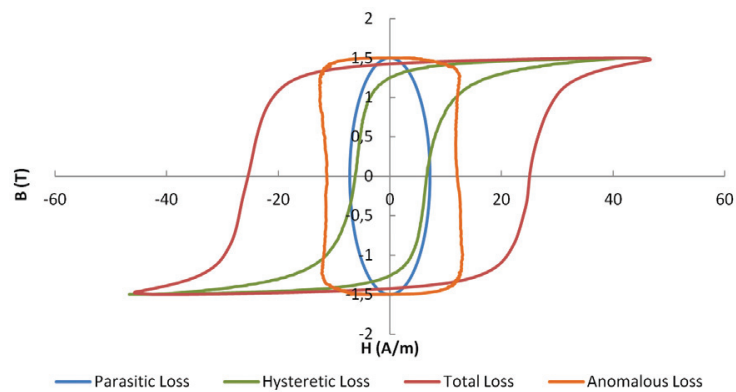

Figure 5. Loss separation for GO samples using peak induction $1.5 \mathrm{~T}$ and frequency $60 \mathrm{~Hz}$.

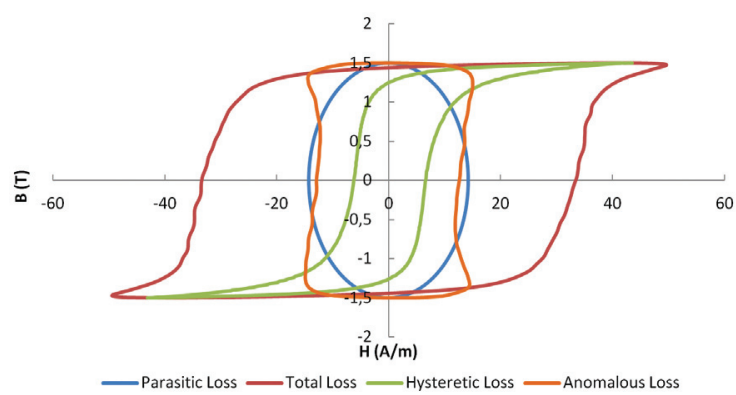

Figure 6. Loss separation for GO samples using peak induction $1.5 \mathrm{~T}$ and frequency $100 \mathrm{~Hz}$.

The energy dissipation mechanisms in electrical steels are associated with displacement, nucleation and annihilation of domain walls ${ }^{6-8}$. According to Landgraf ${ }^{13}$, along the low induction region (for induction ranging from -0.8 to $0.8 \mathrm{~T}$ ) the main mechanism of energy dissipation is domain wall movement. The results for non oriented steel reveal that most of the anomalous loss activity takes place in the low induction region and it is concentrated in the first and third quadrants. The excess loss decreases in the high induction region, where the magnetization by irreversible magnetic domains rotation prevails.

Figures 5 and 6 show the anomalous loss behavior for grain oriented samples. In opposition to the observed for non oriented steel, anomalous loss presents a remarkable participation at the high induction region. This different behavior can be associated with magnetic domain structure. In non oriented steels, that structure is complex due to the different grain orientations. On the other hand, in grain oriented sheets, one can use a model proposed by Pry and Bean ${ }^{14}$, which assume a periodic organization of magnetic domains. Besides that, Shilling and Houze ${ }^{15}$ proposed the existence of lancet domains. The annihilation and nucleation of these domains during the magnetization process have a great contribution for the anomalous loss increase as reported in ${ }^{16,17}$.

\section{Conclusion}

The parcels that compose the total loss can be represented graphically using the procedure described in this paper. Using that procedure, it was observed that the anomalous loss exhibits a different behavior during a magnetization cycle when non oriented and grain oriented 
steels are compared. In non oriented steels, anomalous loss is concentrated in the low induction region. On the other hand, in grain oriented samples, the results indicate remarkable participation of anomalous loss in high induction region. In this case, there is influence of the lancet domains nucleation/ annihilation phenomenon.

\section{References}

1. Moses AJ. Electrical steels: past, present and future developments. IEE Procedings. 1990; 137(Pt. A 5).

2. Barros J, Schneider J, Verbeken K and Houbaert Y. On the correlation between microstructure and magnetic losses in electrical steel. Journal of Magnetism and Magnetic Materials. 2008; 320:2490-2493. http://dx.doi.org/10.1016/j. jmmm.2008.04.056

3. Campos MF, Teixeira JC and Landgraf FJG. The optimum grain size for minimizing energy losses. Journal of Magnetism and Magnetic Materials. 2008; 301:94-99. http://dx.doi. org/10.1016/j.jmmm.2005.06.014

4. Rodrigues-Junior DL, Silveira JRF and Landgraf JGF. Combining Mager and Steinmetz: The Effect of Grain Size and Maximum Induction on Hysteresis Energy Loss. IEEE Transactions on Magnetics. 2011; 47(9).

5. Bertotti G. General properties of power losses in soft ferromagnetic materials. IEEE Transactions on Magnetics. 1988; 24:624-630.

6. Boon CR and Robey JA. Effect of domain-wall motion on power loss in grain-oriented silicon-iron sheet. Proceedings of the Institution ofElectrical Engineers. 1968; 115:1535-1540. http://dx.doi.org/10.1049/piee.1968.0271

7. Haller TR and Kramer JJ. Model for Reverse-Domain Nucleation in Ferromagnetic Conductors. Journal of Applied Physics. 1970; 41:1036-1037. http://dx.doi. org/10.1063/1.1658805

8. Goodenough JB. Summary of losses in magnetic materials. IEEE Transactions on Magnetics. 2002; 38:3398-3408. http:// dx.doi.org/10.1109/TMAG.2002.802741

9. American Society for Testing and Materials - ASTM. E 112 1996: Standard Test Methods for Determining Average Grain Size. West Conshohocken: ASTM International; 2004.

\section{Acknowledgements}

The authors thank Brasmetal Waelzholz SA, Aperam South America and Instituto de Pesquisas Tecnológicas - IPT. Daniel L. Rodrigues-Jr and Adriano A. Almeida wish acknowledge the financial support of CAPES.

10. Bertotti G. Hysteresis in magnetism for physicists, Materials Scientists, and Engineers. Academic Press; 1998. p. 400-404.

11. Campos MF, Yonamine T, Fukuhara M, Landgraf FJG, Achete $\mathrm{CA}$ and Missell FP. Effect of Frequency on the Iron Losses of $0.5 \%$ and $1.5 \%$ Si Nonoriented Electrical Steels. IEEE Transactions on Magnetics. 2006; 42(10):2812-2814. http:// dx.doi.org/10.1109/TMAG.2006.879897

12. Thomson JJ. On the heat produced by eddy currents in an iron plate exposed to an alternating magnetic. Electrician. 1892; 28:599-600.

13. Landgraf FJG, Teixeira JC, Emura M, Campos MF and Muranaka CS. Separating components of the hysteresis loss of non-oriented electrical steels. Materials Science Forum. 1999; 302-303:440-445. http://dx.doi.org/10.4028/ www.scientific.net/MSF.302-303.440

14. Pry $\mathrm{H}$ and Bean CP. Calculation of the Energy Loss in Magnetic Sheet Materials using a Domain Model. Journal of Applied Physics. 1958: 29:532. http://dx.doi.org/10.1063/1.1723212

15. Shilling JW and Houze GL Jr. Magnetic properties and Domain Structure in Grain-Oriented 3\% Si-Fe. IEEETransactions on Magnetics. 1974; 10(2):195-223. http://dx.doi.org/10.1109/ TMAG.1974.1058317

16. Shilling JW, Morris WG, Osborn ML and Prakash R. Orientation Dependence of Domain Wall Spacing and Losses in 3-Percent Si-Fe Single Crystals. IEEETransactions on Magnetics. 1978; 14(3):104-111. http://dx.doi.org/10.1109/ TMAG.1978.1059739

17. Ushigami Y, Mizokami M, Fujikura M, Kubota T, Fujii H and Murakami K. Recent development of low-loss grainoriented silicon steel. Journal of Magnetism and Magnetic Materials. 2003; 5(3):307-314. http://dx.doi.org/10.1007/ BF02649332 